\title{
Influência dos Níveis de Umidade na Colheita e nas Temperaturas de Secagem de Grãos de Trigo sobre Desempenho, Rendimento e Composição de Carcaça de Frangos de Corte ${ }^{1}$

\author{
Valdir Silveira de Ávila², Helenice Mazzuco², José Antonio Portella ${ }^{3}$, Jorge Victor Ludke²,
} Arlei Coldebella ${ }^{2}$
}

\begin{abstract}
RESUMO - Foi avaliada a influência da umidade na colheita (U) e da temperatura de secagem do grão de trigo em dietas isoprotéicas, isoenergéticas e isovolumétricas sobre o desempenho de frangos de corte. Os tratamentos aplicados aos grãos constituíram na colheita com 30,16 ou $13 \%$ de $\mathrm{U}$ e secagem às temperaturas de 100,70 ou $40^{\circ} \mathrm{C}$, exceto para o último valor de $\mathrm{U}$, que permaneceu sem secagem. As dietas foram fornecidas em três fases (1-21, 22-35 e 36-42 dias), avaliando-se os parâmetros ganho de peso (GP), consumo de ração (CR) e conversão alimentar (CA). Aos 21 e 42 dias de idade, uma ave representante da média de peso do boxe foi abatida, para avaliação da composição proximal e energia bruta (EB) da carcaça. Não houve diferença significativa entre os tratamentos para essas variáveis em ambas as idades. De modo geral, as dietas em que o trigo foi incluído contribuíram com índices de desempenho superiores à dieta controle, de modo que o contraste controle versus dietas à base de trigo foi significativo nos três períodos para GP, nos dois últimos períodos para CR e somente de 1-21 dias para CA. Aos 42 dias de idade, uma ave representante do peso médio do boxe foi abatida, para avaliação dos cortes nobres e da carcaça. O peso da carcaça eviscerada foi superior para os tratamentos contendo trigo em relação ao tratamento controle. A inclusão de trigo (da mesma lavoura e ano) em torno de 50\% na dieta de frangos de corte, mostrou-se viável em substituição ao milho, durante todo o ciclo de produção das aves (1-42 dias), independentemente dos níveis de umidade na colheita e da temperatura de secagem dos grãos.
\end{abstract}

Palavras-chave: composição proximal, cortes nobres, frango, trigo

\section{Effect of Wheat Harvested under Different Humidity Levels, Processed at Different Drying Temperatures on Performance, Carcass Traits and Chemical Composition of Male Broilers}

\begin{abstract}
This study was conducted to evaluate the influence of humidity levels at harvesting period and drying temperatures of wheat grain in isoprotein, isoenergy and isovolumetric diets on broiler performance. The wheat grains were harvested with 30,16 and $13 \%$ of humidity levels and submitted to drying temperatures of 100,70 and $40^{\circ} \mathrm{C}$. The level of $13 \%$ of humidity was not submitted to drying. The diets were offered to birds in three distinct periods, 1-21; 22-35 and 36-42 days of age. The parameters evaluated were body weight gain, feed:gain ratio, feed intake and weight gain. During the three evaluated periods the body weight gain and during $22-$ 35 days and 36-42 days the feed intake of broilers submitted to diets with wheat were higher. Feed:gain ratio of broilers submitted to wheat diets during the 1-21 days period were lower. At 21 and 42 days of age, one bird representing the average body weight of each replicate was selected for processing and evaluation of carcass nutrient composition and crude energy content, however there were no differences for these parameters at both ages. Birds representing the average body weight of all replicates were processed for determination of carcass yield at 42 days of age. In absolute terms carcass weights were higher than birds under the treatment with wheat, in spite of humidity at harvest and the following drying temperature applied. Inclusion of wheat in broiler diets in levels of $50 \%$ in substitution of corn is technically feasible during all the raising period (1 - 42 days), in spite of humidity at harvest and drying temperature.
\end{abstract}

Key Words: broiler, carcass characteristics, chemical composition, wheat

\section{Introdução}

As perdas quantitativas durante os processos de colheita, secagem, transporte e armazenamento de grãos no Brasil foram estimadas em $20 \%$ da produção anual (Brasil, 1993) e estão relacionadas à qualidade do grão, proporcionada por fatores de colheita, secagem e armazenagem. O ponto de colheita inadequado, quando o grão permanece muito tempo na lavoura, após a maturação fisiológica, e o processo de secagem - com temperaturas inadequadas para o teor de umidade do grão - contribuem com alterações

${ }^{1}$ Projeto financiado pela Empresa Brasileira de Pesquisa e Agropecuária - Embrapa.

2 Embrapa Suínos e Aves, Caixa Postal 21, CEP: 89700-00, Concórdia - SC (vavila@cnpsa.embrapa.br; helenice@cnpsa.embrapa.br; jorge@cnpsa.embrapa.br; acoldebe@cnpsa.embrapa.br).

3 Embrapa Trigo, Caixa Postal 451, CEP: 99001-970, Passo Fundo, RS (portella@cnpt.embrapa.br). 
indesejáveis na qualidade do mesmo. Quando se consideram as condições de colheita do grão (umidade) e seu posterior processamento (secagem) são esperadas alterações na qualidade do produto final que influem decisivamente em seu emprego na alimentação.

Os parâmetros qualitativos de grãos são acompanhados pelas agroindústrias por meio de tabelas de composição nutritiva dos alimentos que podem compor uma dieta animal. No entanto, em função de fatores como umidade e temperatura de secagem dos grãos, esses parâmetros podem sofrer grande variação e, portanto, os valores presentes nas tabelas de composição de alimentos não refletem essa variabilidade.

Ingredientes alternativos, como o trigo, na substituição do principal componente energético das rações (milho) para frangos de corte, têm recebido atenção em várias publicações recentes (Faria Filho et al., 2000; Brum, 2000; Lima et al., 1998). Segundo Lima et al.(1998), a composição do trigo é bastante variável e essas diferenças são atribuídas ao cultivar utilizado e às variações climáticas e de fertilidade do solo. A intervenção na secagem e a umidade na colheita propiciam maior valor nutricional ao trigo (Mazzuco et al., 2000). Do mesmo modo, Scott et al. (1998) comprovaram que os valores de energia metabolizável do trigo podem variar de acordo com a variedade e o tipo de cereal (Triticum durum ou Triticum aestivum), o ambiente em que o cereal é cultivado e a presença de fatores antinutritivos que podem limitar a disponibilidade dos nutrientes às aves.

Conforme Biagi et al. (1996), os grãos e outros produtos agrícolas deveriam ser colhidos no ponto de maturação fisiológica, quando apresentam teores máximos de amido, proteínas e óleos e teor de umidade elevada, mas esta última condição propicia rápida deterioração do produto.

Nesse sentido, objetivou-se no presente estudo comparar, a partir do desempenho, cortes nobres e composição de carcaça de frangos de corte, uma dieta a base de milho com dietas à base de trigo colhidos com diferentes níveis de umidade e processados sob diferentes temperaturas de secagem.

\section{Material e Métodos}

O experimento foi conduzido no período de fevereiro a abril de 2000. Foram utilizados 1904 pintos sexados (machos) da linhagem Ross com um dia de idade, distribuídos em delineamento casualizado em blocos por peso inicial médio. As unidades experimentais foram constituídas por 34 aves, distribuídas em boxes, e sete repetições dos seguintes tratamentos: uma dieta de milho e farelo de soja (controle); sete dietas à base de trigo (em substituição à maior parte do milho) e farelo de soja - o trigo utilizado no estudo foi colhido com 30 e $16 \%$ de umidade e submetido à secagem com temperaturas de 100,70 e $40^{\circ} \mathrm{C}$; e um tratamento utilizando trigo colhido com $13 \%$ de umidade e sem secagem, constituindo, assim, oito dietas experimentais.

Foi utilizado trigo da cultivar Embrapa BRS49, da mesma safra e lavoura (1999), submetido à secagem com temperatura monitorada em secador de leito fixo nas Unidades Experimentais da Embrapa Trigo, Passo Fundo-RS. A composição proximal, os valores de energia bruta (EB), de energia metabolizável aparente corrigida para nitrogênio (EMAn), determinada em ensaio de metabolismo pelo método de coleta total de acordo com Albino (1981), o peso hectolitro (PH) e o peso de mil grãos (PMG) dos trigos foram avaliados.

As aves foram submetidas à dietas isocalóricas, isoprotéicas e isovolumétricas, fornecidas à vontade em um programa de alimentação de três fases inicial (1-21), de crescimento (22-35) e final (36-42 dias), contendo seqüencialmente 21,$7 ; 20,3$ e $18,5 \%$ de proteína bruta (PB) e 3087, 3172 e $3200 \mathrm{kcal} / \mathrm{kg}$ de energia metabolizável (Tabela 1). Com base nos valores da matéria seca de cada amostra de trigo, as rações foram formuladas de forma isovolumétrica. A dieta com o trigo colhido com $13 \%$ de umidade foi utilizada como padrão para o cálculo das demais. A diferença no teor de matéria seca entre os trigos foi corrigida adicionando-se água.

Acompanhou-se o desempenho das aves a partir do ganho de peso (GP), do consumo de ração (CR) e da conversão alimentar (CA) nos períodos 1-21, 22-35 e 36-42 dias de idade. Aos 21 dias de idade, uma ave por repetição foi selecionada conforme o peso médio apresentado no boxe (Guidoni et al., 1995), para avaliação da composição proximal (proteína bruta [PB], matéria seca [MS], extrato etéreo [EE] e matéria mineral [MM]) e de EB. Aos 42 dias de idade, duas aves por boxe foram selecionadas e abatidas - uma para avaliaçãoe rendimento de carcaça e a outra para avaliação da composição proximal e dos valores de EB. As análises de composição química e EB dos ingredientes, excretas e carcaça foram realizadas no laboratório de Nutrição Animal da Embrapa Suínos e Aves, de acordo com a AOAC (1984) e Parr Instruments Co. (1984).

\section{R. Bras. Zootec., v.33, n.6, p.1467-1476, 2004}


Tabela 1 - Composição percentual e níveis nutricionais das rações experimentais Table 1 - Percentage composition and nutritional levels of the experimental diets

\begin{tabular}{|c|c|c|c|c|c|c|}
\hline \multirow{3}{*}{$\begin{array}{l}\text { Ingredientes } \\
\text { Ingredient }\end{array}$} & \multicolumn{6}{|c|}{$\begin{array}{l}\text { Fase } \\
\text { Period }\end{array}$} \\
\hline & \multicolumn{2}{|c|}{$\begin{array}{l}1-21 \text { dias } \\
1-21 \text { days }\end{array}$} & \multicolumn{2}{|c|}{$\begin{array}{l}22-35 \text { dias } \\
22-35 \text { days }\end{array}$} & \multicolumn{2}{|c|}{$\begin{array}{l}36-42 \text { dias } \\
36-42 \text { days }\end{array}$} \\
\hline & $\begin{array}{l}\text { Controle } \\
\text { Control }\end{array}$ & $\begin{array}{l}\text { Trigo } \\
\text { Wheat }\end{array}$ & $\begin{array}{l}\text { Controle } \\
\text { Control }\end{array}$ & $\begin{array}{l}\text { Trigo } \\
\text { Wheat }\end{array}$ & $\begin{array}{c}\text { Controle } \\
\text { Control }\end{array}$ & $\begin{array}{l}\text { Trigo } \\
\text { Wheat }\end{array}$ \\
\hline $\begin{array}{l}\text { Milho } \\
\text { Corn }\end{array}$ & 51,93 & 6,00 & 54,96 & 7,20 & 60,50 & 9,50 \\
\hline $\begin{array}{l}\text { Farelo de soja } \\
\text { Soybean meal }\end{array}$ & 39,04 & 31,03 & 35,76 & 27,91 & 30,91 & 22,00 \\
\hline $\begin{array}{l}\text { Trigo } \\
\text { Wheat }\end{array}$ & - & 50,61 & - & 52,32 & - & 56,26 \\
\hline $\begin{array}{l}\text { Oleo de soja } \\
\text { Soybean oil }\end{array}$ & 4,69 & 7,65 & 5,56 & 8,70 & 5,00 & 8,27 \\
\hline $\begin{array}{l}\text { Fosfato bicálcico } \\
\text { Dicalcium phosphate }\end{array}$ & 2,00 & 1,94 & 1,82 & 1,74 & 1,74 & 1,66 \\
\hline $\begin{array}{l}\text { Calcário } \\
\text { Limestone }\end{array}$ & 1,15 & 1,30 & 1,11 & 1,25 & 1,09 & 1,26 \\
\hline $\begin{array}{l}\text { Sal } \\
\text { Salt }\end{array}$ & 0,35 & 0,37 & 0,35 & 0,37 & 0,37 & 0,36 \\
\hline $\begin{array}{l}\text { DL-Metionina } \\
\text { DL-Methionine }\end{array}$ & 0,22 & 0,22 & 0,10 & 0,10 & 0,14 & 0,15 \\
\hline $\begin{array}{l}\text { L-Lisina } \\
\text { L-Lysine }\end{array}$ & 0,06 & 0,24 & - & 0,04 & - & 0,21 \\
\hline $\begin{array}{l}\text { L-Treonina } \\
\text { L-Threonine }\end{array}$ & 0,08 & 0,16 & - & 0,03 & - & 0,08 \\
\hline $\begin{array}{l}\text { Tylan }-40 \\
\text { Tylan } 40\end{array}$ & 0,03 & 0,03 & 0,02 & 0,02 & - & - \\
\hline $\begin{array}{l}\text { Anticoccidiano } \\
\text { Anticoccidial }^{3}\end{array}$ & 0,06 & 0,06 & 0,06 & 0,06 & - & - \\
\hline $\begin{array}{l}\text { Cloreto de colina }(70 \%) \\
\text { Choline chloride }\end{array}$ & 0,21 & 0,21 & 0,11 & 0,11 & 0,10 & 0,10 \\
\hline $\begin{array}{l}\text { Premix vitamínico } \\
\text { Vitamin }^{1}\end{array}$ & 0,13 & 0,13 & 0,10 & 0,10 & 0,10 & 0,10 \\
\hline $\begin{array}{l}\text { Premix mineral }^{2} \\
\text { Minerals }^{2}\end{array}$ & 0,05 & 0,05 & 0,05 & 0,05 & 0,05 & 0,05 \\
\hline $\begin{array}{l}\text { Composição calculada } \\
\text { Calculated composition }\end{array}$ & & & & & & \\
\hline $\begin{array}{l}\text { Proteína bruta }(\%) \\
\text { Crude protein }(\%)\end{array}$ & 21,69 & 21,69 & 20,25 & 20,25 & 18,5 & 18,5 \\
\hline $\begin{array}{l}\text { Energia metabolizável }(\mathrm{kcal} / \mathrm{kg}) \\
M E, \mathrm{kcal} / \mathrm{kg}\end{array}$ & 3087 & 3087 & 3172 & 3172 & 3200 & 3200 \\
\hline $\begin{array}{l}\text { Cálcio }(\%) \\
\text { Calcium }(\%)\end{array}$ & 0,95 & 0,95 & 0,89 & 0,88 & 0,85 & 0,85 \\
\hline $\begin{array}{l}\text { Fósforo disponível (\%) } \\
\text { Available phosphorus (\%) }\end{array}$ & 0,50 & 0,50 & 0,46 & 0,46 & 0,44 & 0,44 \\
\hline $\begin{array}{l}\text { Metionina digestível (\%) } \\
\text { Digestible methionine (\%) }\end{array}$ & 0,50 & 0,51 & 0,39 & 0,37 & 0,41 & 0,39 \\
\hline $\begin{array}{l}\text { Metionina + Cistina digestível }(\%) \\
\text { Digestible methionine + Cystine }(\%)\end{array}$ & 0,81 & 0,81 & 0,67 & 0,67 & 0,67 & 0,67 \\
\hline $\begin{array}{l}\text { Lisina digestível (\%) } \\
\text { Digestible lysine (\%) }\end{array}$ & 1,12 & 1,12 & 1,00 & 1,00 & 0,89 & 0,89 \\
\hline $\begin{array}{l}\text { Triptofano digestível (\%) } \\
\text { Digestible tryptophan (\%) }\end{array}$ & 0,23 & 0,24 & 0,22 & 0,22 & 0,20 & 0,19 \\
\hline
\end{tabular}

1 Suplementou-se por kg da dieta (Vitamin suplement composition):Vit. A $10.000 \mathrm{UI}$; Vit. $\mathrm{D}_{3} 2.500 \mathrm{UI}$; Vit. E 3,50 mg; Vit. K 3 mg; Vit.B (tiamin) 2,20 mg; Vit. B2 (riboflavin) $6 \mathrm{mg}$; niacina (niacin) $50 \mathrm{mg}$; ácido pantotênico (Pantothenic acid) $12 \mathrm{mg}$; Vit. $\mathrm{B}_{6} 4 \mathrm{mg}$; ácido fólico(Folic acid) $1 \mathrm{mg}$; biotina (biotin) $0,10 \mathrm{mg}$; Vit. $\mathrm{B}_{12} 20 \mathrm{mcg}$.

2 Suplementou-se por kg da dieta (Mineral suplement composition): manganês (manganese) $70 \mathrm{mg}$; zinco (zinc) 50 mg; ferro (iron) $60 \mathrm{mg}$; cobre (copper) $8 \mathrm{mg}$; iodo (iodine) $0,50 \mathrm{mg}$; selênio (selenium) $0,25 \mathrm{mg}$.

${ }^{3}$ Coban $-20 \%$ de monensina sódica (monensin) 
Nas análises estatísticas, utilizou-se o pacote SAS, sendo considerado o modelo para o delineamento em blocos inteiramente casualizados para a análise da variância. Para contemplar o esquema fatorial de tratamentos ( 2 umidades de colheita $\times 3$ temperaturas de secagem), mais 2 tratamentos adicionais (controle e trigo sem secagem), foram testados os contrastes: 1) controle versus dietas contendo trigo; 2) trigo sem secagem versus trigo com secagem; 3) efeito de temperatura; 4) efeito de umidade e 5) efeito da interação entre umidade e temperatura. $\mathrm{O}$ nível de significância adotado para o teste $\mathrm{F}$ foi de $5 \%$.

\section{Resultados e Discussão}

Os valores da composição proximal e de EB e EMAn, PH e PMG do trigo na matéria natural são apresentados na Tabela 2, conforme metodologia descrita por Mazzuco et al. (2000). Os valores nutricionais são semelhantes aos citados na literatura nacional (Embrapa, 1991; Rostagno, 2000). A EMAn do trigo variou de 3280 a $3397 \mathrm{kcal} / \mathrm{kg}$, valor próximo ao de tabela do milho (3390 kcal/kg) (Embrapa, 1991). Os valores de MS, PB, FB dos trigos (Tabela 2) foram superiores aos valores relatados por Nunes et al. (2000). No entanto, para as variáveis EE, Ca, P e EMAn, os valores foram inferiores aos apresentados pelo último autor. Segundo Choct et al.(1999), a qualidade nutritiva do trigo é bastante dependente das condições climáticas durante o ano de colheita. Os mesmos autores encontraram diferenças significativas no conteúdo protéico e em amido do trigo e atribuíram tais variações ao local e ano da colheita. Concluíram que aproximadamente $40 \%$ das safras de trigos acompanhadas durante três anos, apresentaram valores baixos de EMA (abaixo de $3107 \mathrm{kcal} / \mathrm{kg}$ ), o que foi atribuído às variações climáticas (seca ou umidade extremas durante o período de crescimento da planta). No mesmo estudo, o conteúdo protéico dos grãos variou significativamente $(p<0,01)$, em função do local da colheita, sendo o maior valor $14,82 \%$ e o menor $11,23 \%$.

Wiseman \& Inboor (1990), em uma revisão sobre o valor nutricional do trigo para as aves, registraram alguns valores de EMAn com base na matéria seca, mensurados por diferentes autores, evidenciando a magnitude da variabilidade inerente aos diferentes manejos de colheita aplicados ao grão e metodologia de obtenção desses valores para as aves. Com valores de 2474 a $3960 \mathrm{kcal} / \mathrm{kg}$, baseados em mais de 170

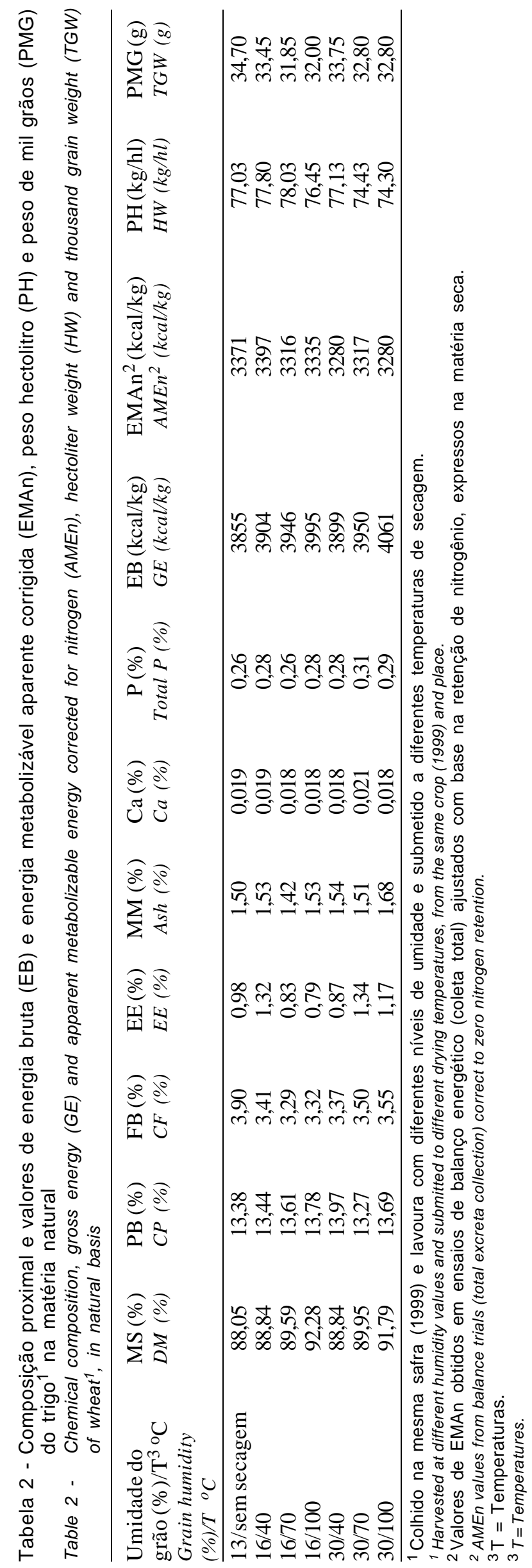


amostras de trigo, os autores demonstraram o grande desafio na predição da EMAn em uma dieta balanceada, considerando o trigo como principal ingrediente energético. Wiseman (2000) concluiu que não houve qualquer relação entre $\mathrm{PH}$ e PMG e valor da energia do trigo para aves e suínos. No estudo, o principal objetivo foi relacionar as mensurações físicas efetuadas nos grãos com os valores nutricionais apresentados pelos mesmos, sendo que os valores de EMA com base na matéria seca variaram de 2029$2975 \mathrm{kcal} / \mathrm{kg}$. A amplitude da variação apresentada foi atribuída a diferenças de variedade e local.

Lopes \& Elias (2000), estudando a influência da umidade de colheita (18 e 20\%) e das condições de secagem (intermitente a $70^{\circ} \mathrm{C}$, estacionária a $45^{\circ} \mathrm{C}$ e processo sem aquecimento) sobre a conservação e qualidade tecnológica do trigo (cultivar Embrapa 16), concluíram que o tipo de processo de secagem não acarretou diferenças significativas sobre estas variáveis. O tratamento que incluiu trigo considerado seco na lavoura (umidade próxima a 13\%) apresentou qualidade inferior e menor conservação no armazenamento.

As análises da variância para o efeito das dietas experimentais no desempenho de frangos de corte de 1-42 dias de idade encontram-se na Tabela 3.

Nos três períodos considerados (1-21, 1-35 e 142 dias de idade), o teste $F$ não acusou diferenças significativas $(p>0,05)$ para todas as causas de variação envolvendo as dietas à base de trigo (trigo s/secagem vs. trigo c/secagem, temperatura, umidade, temperatura $\times$ umidade), indicando que os diferentes fatores associados a essas dietas não influenciaram significativamente o desempenho das aves. Contudo, o contraste controle vs. trigo foi significativo $(\mathrm{p} \leq 0,01)$ nos três períodos para GP, nos dois últimos períodos para $\mathrm{CR}$, e somente de 1-21 dias para CA. De modo geral, as dietas em que o trigo foi incluído contribuíram com índices de desempenho superiores à dieta-controle (Figura 1).

Brum et al. (2000) também observaram desempenho superior de frangos submetidos a dietas com 50 ou $100 \%$ de trigo em substituição ao milho. Da mesma forma, Faria Filho et al. (2000), utilizando $45 \%$ de trigo inteiro em dietas de frangos de corte no período de 21-42 dias de idade obtiveram médias de conversão alimentar satisfatórias, além de peso corporal e consumo de ração $10 \%$ superiores ao tratamento testemunha.

Contrariando os resultados do presente estudo, Viola et al. (1996) concluíram que houve resposta
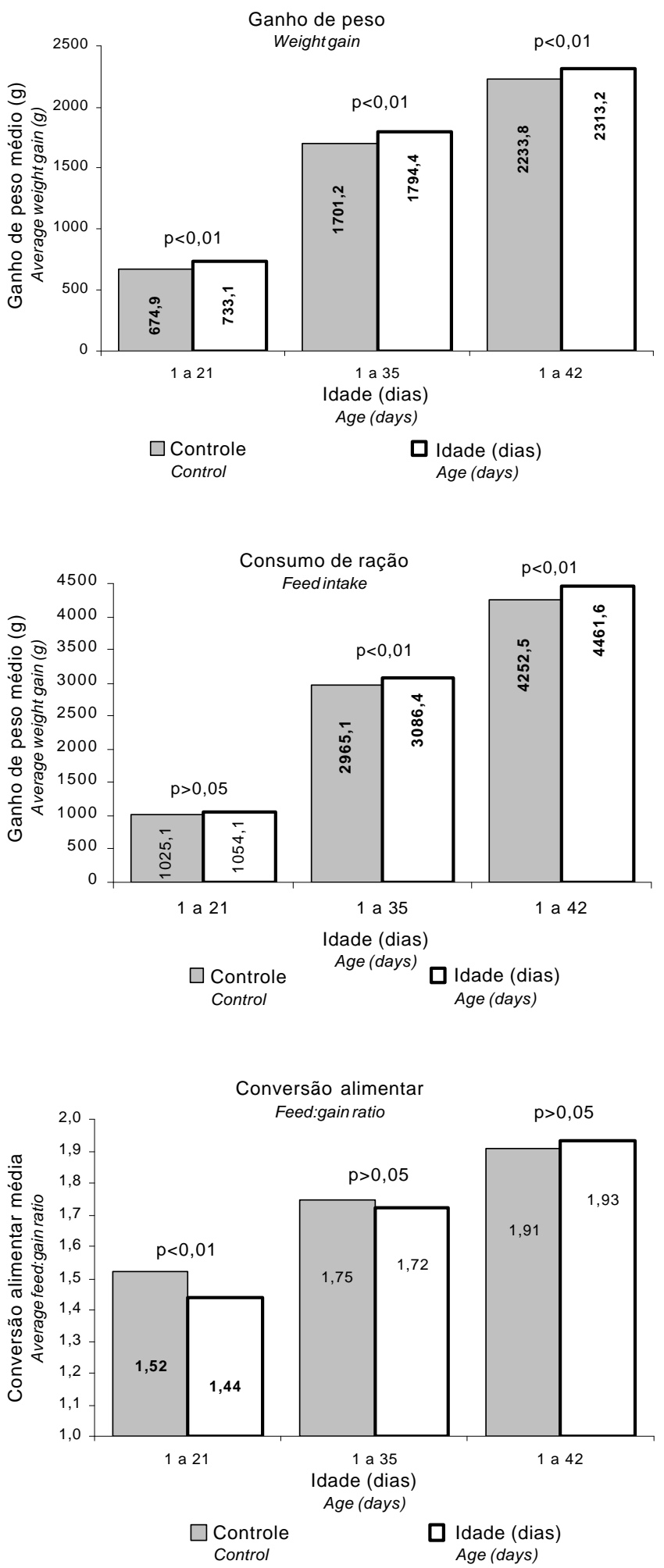

Figura 1 - Médias observadas para as variáveis relacionadas ao desempenho dos frangos de corte nos períodos estudados, em função da dieta-controle e das dietas contendo trigo e nível descritivo de probabilidade do teste $\mathrm{F}$.

Figure 1 - Observed means for the performance variables of broilers in the periods studied, in function of the control diet and of the diets with wheat, and p-value by $F$ test. 
Tabela 3 - Análise da variância, média e teste $\mathrm{F}$ para as variáveis relacionadas ao desempenho de frangos de corte nos períodos estudados

Table 3 - Analysis of variance, mean and $F$ test for the variables related to broilers performance in the periods studied

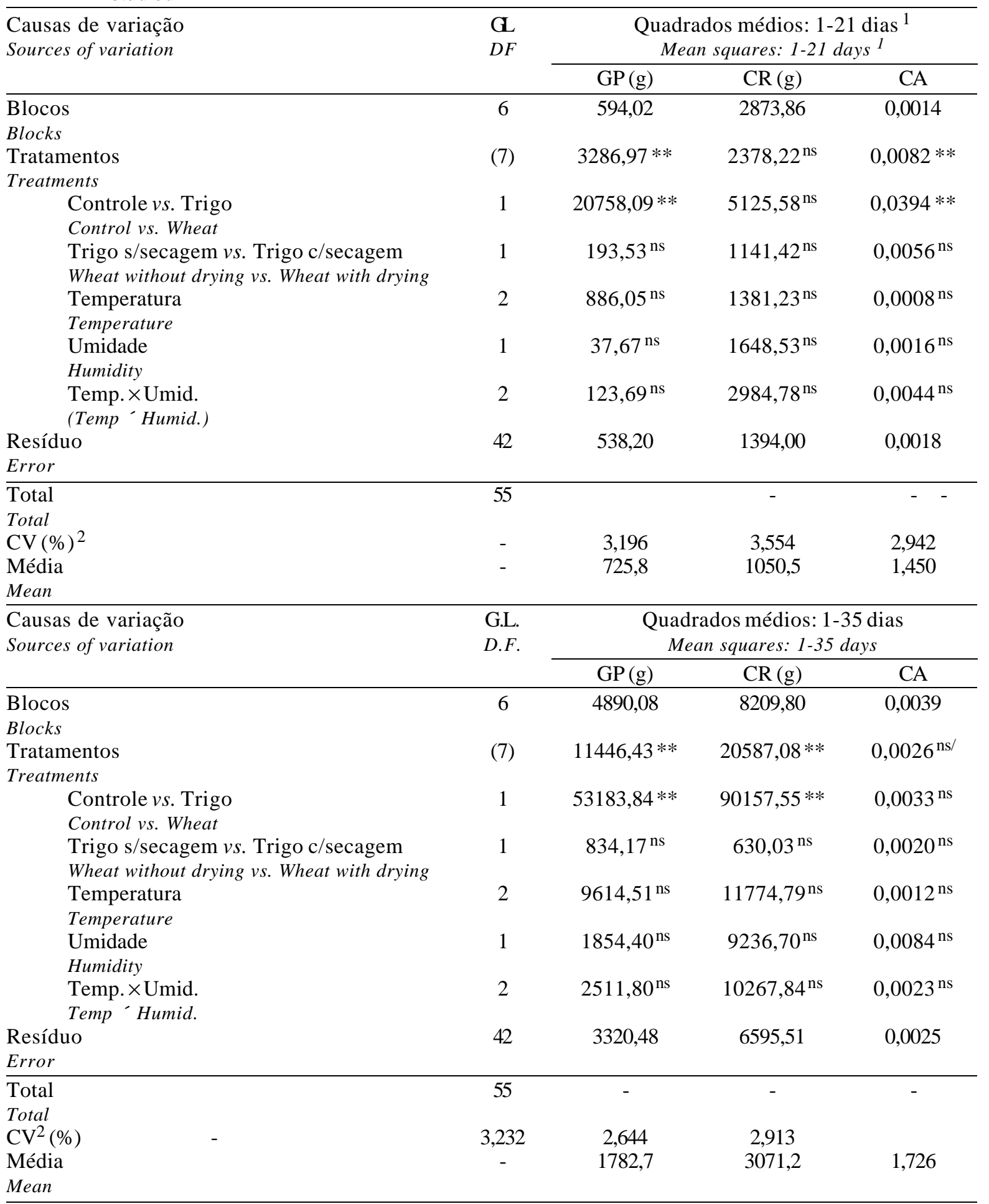

Continua na próxima página... 
Continuação da Tabela 3...



linear negativa no desempenho de frangos de corte em função do nível de inclusão do trigo.

Estudos sobre os efeitos do uso do trigo no desempenho e rendimento de carcaça de frangos de corte são oportunos, levando-se em conta o alto custo do milho em algumas épocas do ano (Faria Filho et al., 2000). A possibilidade de inclusão do trigo em substituição ao milho, aliada aos resultados de desempenho obtidos, é indicativo da viabilidade do emprego desse cereal nas dietas de frango de corte.

As análises da variância para peso de peito, de coxa, de sobrecoxa e de carcaça de frangos abatidos aos 42 dias de idade são apresentadas na Tabela 4.

Os pesos de peito, de coxa e de sobrecoxa não foram influenciados significativamente $(p>0,05)$ por todas as causas de variação estudadas, enquanto, para o peso da carcaça, o teste $\mathrm{F}$ acusou diferença significativa $(\mathrm{p}<0,01)$ para o contraste controle versus trigo.

Numericamente, as médias encontradas para as variáveis relacionadas a peso de cortes nobres e de carcaça foram maiores para as dietas à base de trigo, quando comparadas com as da dieta controle, apesar de não haver diferenças significativas para peito, coxa e sobrecoxa (Tabela 5).

Pieniz et al. (1996), embora tenham avaliado trigo germinado, concluíram que este ingrediente pode substituir integralmente o milho em rações para frangos de corte, com vantagem para os parâmetros conversão alimentar e peso da carcaça, tendo relação com o presente trabalho.

Para os valores de composição proximal e energia bruta das carcaças inteiras - com pés, cabeça e vísceras - de frangos abatidos aos 21 e 42 dias de idade (Tabela 6 ), o teste $F$ não detectou diferenças significativas $(\mathrm{p}>0,05)$ para o efeito de tratamentos. Assim, apesar de os dois contrastes entre tratamentos (controle versus trigo, para matéria seca aos 21 dias; e efeito de umidade, para proteína bruta aos 42 dias) serem significativos $(\mathrm{p}<0,05)$, os mesmos não devem ser considerados. 
Tabela 4 - Análise da variância, média e teste $\mathrm{F}$ para as variáveis relacionadas ao peso de cortes nobres (g) e da carcaça ${ }^{1}$ (g) de frangos abatidos aos 42 dias de idade

Table 4 - Analysis of variance, mean and $F$ test for the variables of carcass caracteristics $(g)$ of broilers slaughtered at 42 days of age

\begin{tabular}{|c|c|c|c|c|c|}
\hline \multirow{2}{*}{$\begin{array}{l}\text { Causas de variação } \\
\text { Sources of variation }\end{array}$} & \multirow{2}{*}{$\begin{array}{l}\text { G.L. } \\
\text { D.F. }\end{array}$} & \multicolumn{4}{|c|}{$\begin{array}{l}\text { Quadrados médios } \\
\text { Mean squares }\end{array}$} \\
\hline & & $\begin{array}{l}\text { Peito } \\
\text { Breast }\end{array}$ & $\begin{array}{c}\text { Coxa } \\
\text { Drumstick }\end{array}$ & $\begin{array}{l}\text { Sobrecoxa } \\
\text { Thigt }\end{array}$ & $\begin{array}{l}\text { Carcaça } \\
\text { Carcass }\end{array}$ \\
\hline Blocos & 6 & 1270,3 & 411,7 & 581,3 & 11497,9 \\
\hline $\begin{array}{l}\text { Blocks } \\
\text { Tratamentos }\end{array}$ & (7) & $1345,9^{\mathrm{ns}}$ & $75,9^{\mathrm{ns}}$ & $533,8^{\mathrm{ns}}$ & $10165,8 *$ \\
\hline $\begin{array}{l}\text { Treatments } \\
\text { Controle vs. Trigo } \\
\quad \text { Control vs. Wheat }\end{array}$ & 1 & $2654,1^{\mathrm{ns}}$ & $32,6^{\mathrm{ns}}$ & $936,8^{\mathrm{ns}}$ & $41472,0 * *$ \\
\hline $\begin{array}{l}\text { Trigo s/secagem vs. Trigo c/secagem } \\
\text { Wheat without drying vs. Wheat with drying }\end{array}$ & 1 & $1526,9^{\mathrm{ns}}$ & $4,4^{\mathrm{ns}}$ & $12,2^{\mathrm{ns}}$ & $1066,7^{\mathrm{ns}}$ \\
\hline $\begin{array}{l}\text { Temperatura } \\
\text { Temperature }\end{array}$ & 2 & $717,2^{\mathrm{ns}}$ & $190,5^{\mathrm{ns}}$ & $1012,5^{\mathrm{ns}}$ & $12123,8^{\mathrm{ns}}$ \\
\hline $\begin{array}{l}\text { Umidade } \\
\text { Humidity }\end{array}$ & 1 & $1761,5^{\mathrm{ns}}$ & $1,5^{\mathrm{ns}}$ & $219,4^{\mathrm{ns}}$ & $754,4^{\mathrm{ns}}$ \\
\hline $\begin{array}{l}\text { Temp. } \times \text { Umid. } \\
\text { Temp } \times \text { Humid }\end{array}$ & 2 & $1022,2^{\mathrm{ns}}$ & $55,7^{\mathrm{ns}}$ & $271,5^{\mathrm{ns}}$ & $1809,8^{\mathrm{ns}}$ \\
\hline $\begin{array}{l}\text { Resíduo } \\
\text { Error }\end{array}$ & 42 & 1124,2 & 102,9 & 323,0 & 4616,5 \\
\hline Total & 55 & - & - & - & - \\
\hline $\begin{array}{l}\text { Total } \\
\text { CV }^{2}(\%) \\
\text { Média } \\
\text { Mean }\end{array}$ & - & $\begin{array}{l}6,691 \\
501,1\end{array}$ & $\begin{array}{l}4,359 \\
232,7\end{array}$ & $\begin{array}{l}5,287 \\
340,0\end{array}$ & $\begin{array}{c}4,001 \\
1698,1\end{array}$ \\
\hline
\end{tabular}

1 Carcaça eviscerada sem cabeça, miúdos e pés (Carcass with no head, visceral organs and feets).

$2 \mathrm{CV}$ - coeficiente de variação (Coefficient of variation).

** = Significativo, pelo teste $\mathrm{F}$, a $1 \%(\mathrm{p} \leq 0,01)$ (Significant by $F$ test $[p \leq .01]$ ).

* = Significativo, pelo teste $F$, a $5 \%(p \leq 0,05)$ (Significant, by $F$ test [ $p \leq .05]$ ).

ns = Não-significativo, pelo teste $F$, considerando-se nível mínimo de significância de $5 \%(p>0,05)$.

ns $=$ Not significant, by $F$ test $(p>$.05).

Tabela 5 - Médias observadas para as variáveis relacionadas ao peso de cortes nobres e de carcaça ${ }^{1}$ de frangos abatidos aos 42 dias de idade, em função da dieta-controle e das dietas à base de trigo

Table 5 - Observed means for the variables related to carcass caracteristics $(g)$ of slaughter broilers at 42 days of age, in function of the control diet and of the diets with wheat

\begin{tabular}{lcccc}
\hline \multirow{2}{*}{$\begin{array}{l}\text { Tratamentos } \\
\text { Treatments }\end{array}$} & \multicolumn{4}{c}{$\begin{array}{c}\text { Variáveis }(\mathrm{g}) \\
\text { Variables }(\mathrm{g})\end{array}$} \\
\cline { 2 - 5 } & $\begin{array}{c}\text { Peito } \\
\text { Breast }\end{array}$ & $\begin{array}{c}\text { Coxa } \\
\text { Drumstick }\end{array}$ & $\begin{array}{c}\text { Sobrecoxa } \\
\text { Tigh }\end{array}$ & $\begin{array}{c}\text { Carcaça } \\
\text { Carcass }\end{array}$ \\
\hline $\begin{array}{l}\text { Controle } \\
\begin{array}{l}\text { Control } \\
\text { Dietas com trigo }\end{array}\end{array}$ & 483 & 231 & 329 & 1626 \\
$\begin{array}{l}\text { Diets with wheat } \\
\mathrm{p}\end{array}$ & 504 & 233 & 342 & 1708 \\
\hline
\end{tabular}

${ }^{1}$ Carcaça eviscerada sem cabeça, miúdos e pés.

${ }^{1}$ Carcass with no head, visceral organs and feet.

$\mathrm{p}=$ nível descritivo de probabilidade do teste $\mathrm{F}$ para o contraste controle versus trigo.

$p$-value of $F$ test for the control versus wheat contrast.

\section{R. Bras. Zootec., v.33, n.6, p.1467-1476, 2004}


Tabela 6 - Análise da variância, média e teste F para os valores de composição proximal (\%) e energia bruta $(\mathrm{kcal} / \mathrm{kg})$ das carcaças ${ }^{1}$ de frangos abatidos aos 21 e 42 dias de idade

Table 6 - Analysis of variane, mean and $F$ test for the values of chemical composition (\%) and crude energy (kcal/ $\mathrm{kg}$ ) of carcass of male broilers slaughtered at 21 and 42 days of age

Causas de variação

Quadrados médios: 21 dias

Sources of variation

Mean squares: 21 days

\begin{tabular}{|c|c|c|c|c|c|c|}
\hline & D.F. & $\begin{array}{l}\text { bruta } \\
\text { Crude } \\
\text { protein }\end{array}$ & $\begin{array}{c}\text { seca } \\
\text { Dry } \\
\text { matter }\end{array}$ & $\begin{array}{c}\text { etéreo } \\
\text { Ether } \\
\text { extract }\end{array}$ & $\begin{array}{l}\text { bruta } \\
\text { Gross } \\
\text { energy }\end{array}$ & Ash \\
\hline$\overline{\mathrm{Blocos}}$ & 6 & 1,084 & 0,976 & 0,655 & 51531,7 & 0,034 \\
\hline Blocks & & & & & & \\
\hline Tratamentos & (7) & $0,082^{\mathrm{ns}}$ & $0,768^{\mathrm{ns}}$ & $1,395^{\mathrm{ns}}$ & $11151,4^{\mathrm{ns}}$ & $0,004^{\mathrm{ns}}$ \\
\hline $\begin{array}{l}\text { Treatments } \\
\text { Controle vs. Trigo } \\
\text { Control vs. Wheat }\end{array}$ & 1 & $0,083^{\mathrm{ns}}$ & $3,214 *$ & $3,874^{\mathrm{ns}}$ & $28611,7^{\mathrm{ns}}$ & $0,001^{\mathrm{ns}}$ \\
\hline $\begin{array}{l}\text { Trigo s/secagem vs. Trigo c/secagem } \\
\text { Wheat without drying vs. Wheat with drying }\end{array}$ & 1 & $0,004^{\mathrm{ns}}$ & $0,586^{\mathrm{ns}}$ & $1,456^{\mathrm{ns}}$ & $3778,6^{\mathrm{ns}}$ & $0,001^{\mathrm{ns}}$ \\
\hline $\begin{array}{l}\text { Temperatura } \\
\text { Temperature }\end{array}$ & 2 & $0,067^{\mathrm{ns}}$ & $0,414^{\mathrm{ns}}$ & $0,936^{\mathrm{ns}}$ & $27886,9^{\mathrm{ns}}$ & $0,008^{\mathrm{ns}}$ \\
\hline $\begin{array}{l}\text { Umidade } \\
\text { Humidity }\end{array}$ & 1 & $0,060^{\mathrm{ns}}$ & $0,065^{\mathrm{ns}}$ & $0,362^{\mathrm{ns}}$ & $9997,7^{\mathrm{ns}}$ & $0,014^{\mathrm{ns}}$ \\
\hline $\begin{array}{l}\text { Temp. } \times \text { Umid } \\
\text { Temp } \times \text { Humid }\end{array}$ & 2 & $0,147^{\mathrm{ns}}$ & $0,341^{\mathrm{ns}}$ & $1,098^{\mathrm{ns}}$ & $7784,7^{\mathrm{ns}}$ & $0,001^{\mathrm{ns}}$ \\
\hline $\begin{array}{l}\text { Resíduo } \\
\text { Error } \\
\end{array}$ & 42 & 0,368 & 0,698 & 1,552 & 29321,6 & 0,021 \\
\hline Total & 55 & - & - & - & - & - \\
\hline $\begin{array}{l}\text { Total } \\
\text { CV }^{2}(\%) \\
\text { Média } \\
\text { Mean }\end{array}$ & - & $\begin{array}{l}3,913 \\
15,50\end{array}$ & $\begin{array}{l}2,901 \\
28,80\end{array}$ & $\begin{array}{c}15,581 \\
8,00\end{array}$ & $\begin{array}{c}2,980 \\
5746,95\end{array}$ & $\begin{array}{l}6,449 \\
2,26\end{array}$ \\
\hline Causas de variação & \multicolumn{6}{|c|}{$\begin{array}{l}\text { Quadrados médios: } 42 \text { dias } \\
\text { Mean squares: } 42 \text { days }\end{array}$} \\
\hline Sources of variation & $\begin{array}{l}\mathrm{G} \\
D F\end{array}$ & $\begin{array}{c}\text { Proteína } \\
\text { bruta } \\
\text { Crude } \\
\text { protein }\end{array}$ & $\begin{array}{c}\text { Matéria } \\
\text { seca } \\
\text { Dry } \\
\text { matter }\end{array}$ & $\begin{array}{c}\text { Extrato } \\
\text { etéreo } \\
\text { Ether } \\
\text { extract }\end{array}$ & $\begin{array}{c}\text { Energia } \\
\text { bruta } \\
\text { Gross } \\
\text { energy }\end{array}$ & $\begin{array}{l}\text { Cinzas } \\
\text { Ash }\end{array}$ \\
\hline $\begin{array}{l}\text { Blocos } \\
\text { Blocks }\end{array}$ & 6 & 0,906 & 1,769 & 1,440 & 51355,1 & 0,065 \\
\hline $\begin{array}{l}\text { Tratamentos } \\
\text { Treatments }\end{array}$ & (7) & $0,680^{\mathrm{ns}}$ & $2,153^{\mathrm{ns}}$ & $1,589^{\mathrm{ns}}$ & $47491,1^{\mathrm{ns}}$ & $0,047^{\mathrm{ns}}$ \\
\hline $\begin{array}{l}\text { Controle vs. Trigo } \\
\text { Control vs. Wheat }\end{array}$ & 1 & $0,658^{\mathrm{ns}}$ & $0,112^{\mathrm{ns}}$ & $0,830^{\mathrm{ns}}$ & $41348,7^{\mathrm{ns}}$ & $0,008^{\mathrm{ns}}$ \\
\hline $\begin{array}{l}\text { Trigo s/secagem vs. Trigo c/secagem } \\
\text { Wheat without drying vs. Wheat with drying }\end{array}$ & 1 & $0,048^{\mathrm{ns}}$ & $0,107^{\mathrm{ns}}$ & $0,041^{\mathrm{ns}}$ & $16522,5^{\mathrm{ns}}$ & $0,070^{\mathrm{ns}}$ \\
\hline $\begin{array}{l}\text { Temperatura } \\
\text { Temperature }\end{array}$ & 2 & $0,720^{\mathrm{ns}}$ & $3,148^{\mathrm{ns}}$ & $4,649^{\mathrm{ns}}$ & $25027,3^{\mathrm{ns}}$ & $0,047^{\mathrm{ns}}$ \\
\hline $\begin{array}{l}\text { Umidade } \\
\text { Humidity }\end{array}$ & 1 & $2,247 *$ & $6,926^{\mathrm{ns}}$ & $0,511^{\mathrm{ns}}$ & $120535,7^{\mathrm{ns}}$ & $0,128^{\mathrm{ns}}$ \\
\hline $\begin{array}{l}\text { Temp. } \times \text { Umid } \\
\text { Temp } \times \text { Humid }\end{array}$ & 2 & $0,183^{\mathrm{ns}}$ & $0,814^{\mathrm{ns}}$ & $0,220^{\mathrm{ns}}$ & $51988,1^{\mathrm{ns}}$ & $0,015^{\mathrm{ns}}$ \\
\hline $\begin{array}{l}\text { Resíduo } \\
\text { Error }\end{array}$ & 42 & 0,380 & 2,060 & 2,012 & 74310,1 & 0,051 \\
\hline Total & 55 & - & - & - & - & - \\
\hline $\begin{array}{l}\text { Total } \\
\text { CV }^{2}(\%) \\
\text { Média } \\
\text { Mean } \\
\end{array}$ & - & $\begin{array}{l}3,411 \\
18,08\end{array}$ & $\begin{array}{l}4,303 \\
33,36\end{array}$ & $\begin{array}{c}18,964 \\
7,48\end{array}$ & $\begin{array}{c}4,654 \\
5857,46\end{array}$ & $\begin{array}{l}9,576 \\
2,36\end{array}$ \\
\hline
\end{tabular}

1 Ave inteira com penas, cabeça, pés e visceras (Whole bird with feathers, head, feet and visceral organs).

2 CV - Coeficiente de variação (Coefficient of variation).

* Significativo, pelo teste $F$, a $5 \%(p \leq 0,05)$ (Significant, by $F$ test $[p \leq .05]$ ).

ns Não-significativo, pelo teste $F$, considerando-se nível mínimo de significância de $5 \%(p>0,05)$.

ns Not significant, by F test ( $p>$.05). 


\section{Conclusões}

A inclusão de trigo oriundo da mesma lavoura e ano, em níveis de 50,6\% (1-21 dias), 52,3\% (22-35 dias) e 56,3\% (36-42 dias), na dieta de frangos de corte, mostrou-se viável, em substituição ao milho, durante todo o ciclo de produção das aves (1 - 42 dias).

Do ponto de vista nutricional, é viável realizar a colheita antecipada do trigo, independentemente da umidade de colheita e da temperatura de secagem.

\section{Literatura Citada}

ALBINO, L.F.T.; ROSTAGNO, H.S.; FONSECA, J.B. et al. Tabela de composição dos alimentos concentrados. Valores de composição química e de energia determinados com aves em diferentes idades. Revista da Sociedade Brasileira de Zootecnia, v.10, n.1, p.133-146, 1981.

ASSOCIATION OF OFFICIAL ANALYTICAL CHEMISTS AOAC. Official methods of analysis. 14.ed. Arlington: 1984. 1141p.

BIAGI, J.D.; SILVA, L.O.D.; MARTINS, R.R. Importância da qualidade dos grãos na alimentação animal. In: SIMPÓSIO LATINO-AMERICANO DE NUTRIÇÃO ANIMAL; SEMINÁRIO SOBRE TECNOLOGIA DA PRODUÇÃO DE RAÇÕES, 1996, Campinas. Anais... Campinas: Colégio Brasileiro de Nutrição Animal, 1996. p.21-45.

BRASIL. Ministério da Agricultura, do Abastecimento e da Reforma Agrária. Comissão Técnica para Redução das Perdas na Agropecuária. Perdas na agropecuária brasileira: relatório preliminar. Brasília, 1993. v.1.

BRUM, P.A.R.; LIMA, G.J.M.M.; MAZZUCO, H. et al. Efeito do nível de trigo na dieta, do percentual de grãos germinados e da forma física da ração sobre o desempenho de frangos de corte. Revista Brasileira de Zootecnia, v.29, n.1, p.168-176, 2000.

CHOCT, M.; HUGHES, R.J.; ANNISON, G. Apparent metabolisable energy and chemical composition of Australian wheat in relation to environmental factors. Australian Journal of Agricultural Research, v.50, p.447-451, 1999.

EMBRAPA. Centro Nacional de Pesquisa de Suínos e Aves. Tabela de composição química e valores energéticos de alimentos para suínos e aves. 3.ed. Concórdia: EMBRAPACNPSA, 1991. 97p. (EMBRAPA - CNPSA. Documentos, 19).

FARIA FILHO, D.E.; SAKOMURA, N. K.; BASAGLIA, R. et al. Níveis de inclusão de trigo em grão e moído em dietas de frangos de corte. In: REUNIÃO ANUAL DA SOCIEDADE BRASILEIRA DE ZOOTECNIA, 37., 2000, Viçosa, MG. Anais... Viçosa, MG: Sociedade Brasileira de Zootecnia, 2000. p.304.

GUIDONI, A.L.; ROSA, P.S.; BRUM, P.A.R. Tamanho ideal da amostra na experimentação com frangos de corte. In: CONFERÊNCIA APINCO DE CIÊNCIA E TECNOLOGIA AVÍCOLAS, 1995, Curitiba. Anais... Curitiba: FACTA, 1995. p.299-300.
LIMA, G.J.M.M.; ZANOTTO, D.L.; PIENIZ, L.C. et al. $O$ trigo na alimentação de suínos e aves. Concórdia: Embrapa Suínos e Aves, 1998. p.1-3. (Embrapa Suínos e Aves. Comunicado Técnico, 221).

LOPES, V.; ELIAS, M.C. Influência da umidade de colheita e condições de secagem na qualidade tecnológica de grãos de trigo. In: CONGRESSO BRASILEIRO DE CIÊNCIA E TECNOLOGIA DE ALIMENTOS, 17., 2000, Fortaleza. Anais... Fortaleza: SBCTA, 2000. v.1, p.388.

MAZZUCO, H.; MIRANDA, M.Z.; MARTINS, R.R. et al. Valor energético para frangos de corte de trigo moído ou inteiro colhido com diferentes umidades e submetidos a diferentes temperaturas de secagem. In: REUNIÃO ANUAL DA SOCIEDADE BRASILEIRA DE ZOOTECNIA, 37., 2000, Viçosa, MG. Anais... Viçosa, MG: Sociedade Brasileira de Zootecnia, 2000. p.328.

NUNES, R.V.; ROSTAGNO, H.S.; ALBINO, L.F.T. et al. Composição química e valores energéticos do grão e de subprodutos do trigo para pintos de corte. In: REUNIÃO ANUAL DA SOCIEDADE BRASILEIRA DE ZOOTECNIA, 37., 2000, Viçosa, MG. Anais... Viçosa, MG: Sociedade Brasileira de Zootecnia, 2000. p.263.

PARR INSTRUMENTS CO. Instructions for the 1241 and 1242 adiabatic calorimeters. Moline, 1984. 29p. (Parr Manual, 153).

PIENIZ, L.C.; ZANOTTO, D.L.; GUIDONI, A.L. et al. Trigo em substituição ao milho em rações para frangos de corte. In. REIUNIÃO ANUAL DA SOCIEDADE BRASILEIRA DE ZOOTECNIA, 33., 1996, Fortaleza. Anais... Fortaleza: Sociedade Brasileira de Zootecnia, 1996. p.94-95.

SCOTT, T.A.; SILVERSIDES, F.G.; CLASSEN, H.L. et al. A broiler chick bioassay for measuring the feeding value of wheat and barley in complete diets. Poultry Science, v.77, p.449-455, 1998.

ROSTAGNO, H.S. Tabelas brasileiras para aves e suínos: composição de alimentos e exigências nutricionais. Viçosa, MG: Universidade Federal de Viçosa, 2000. 141p.

VIOLA, E.S.; LECZNIESKI, J.; VUADEN, E. et al. Níveis de substituição de milho por trigo em dietas de frangos de corte nas fases de 1 a 21, 21 a 42 dias de idade. In: CONFERÊNCIA APINCO DE CIÊNCIA E TECNOLOGIA AVÍCOLAS, 1996, Curitiba. Anais... Curitiba: FACTA, 1996. p.46.

WISEMAN, J. Correlation between physical measurements and dietary energy values of wheat for poultry and pigs. Animal Feed Science and Technology, v.84, p.1-11, 2000.

WISEMAN, J.; INBOOR, J. The nutritive value of wheat and its effect on broiler performance. In: HARESIGN, W.; COLE, D.J.A. (Eds.) Recent advances in animal nutrition. London: Butterworths, 1990. p.79-102. 